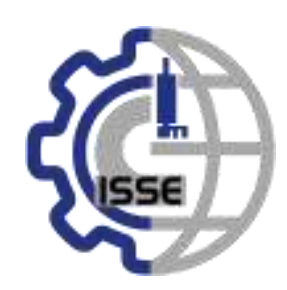

\begin{tabular}{c}
\hline \hline JISSE \\
ISSN: 2636-4425 \\
\hline \hline
\end{tabular}

\title{
Assessment of Stress Distribution Using Equator Attachment in Comparison with Locator Attachment Design
}

\section{(A Three-Dimensional Finite Element Analysis)}

\author{
Mohamed S. A. Ali ${ }^{1, *}$, Hamdi Abo Alfotouh ${ }^{2}$, Mostafa Helmy ${ }^{3}$

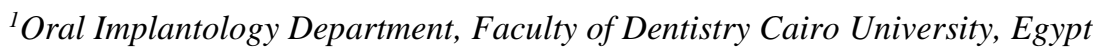 \\ ${ }^{2}$ Removable Prosthodontics Department, Faculty of Dentistry Cairo University, Egypt \\ ${ }^{3}$ Removable Prosthodontics Department, Faculty of Dentistry Cairo University, Egypt
}

A R T I C L E I N F O

Article history:

Received:26-02-2020

Accepted:11-05-2020

Online:17-05-2020

\section{Keywords:}

Equator

Locator

Attachments

Overdenture

Stress

\begin{abstract}
A B S T R A C T
Objective: aiming to evaluate stress distribution in addition to compare different types of lowprofile attachments for implant-retained mandibular overdenture.

Materials and methods: The present study a simulated mandible the two attachments were examined after application of vertical and oblique $45^{\circ}$ loads on the region of the premolar/molar. The results show Equators received less Von Mises stress than locators by about $40 \%$ under vertical loading. On the other hand, under oblique loading locators showed better performance and less Von Mises stress by about $10 \%$. Conclusions: Equator attachment can be considered equivalent to locator attachment, while it may have better performance in certain situations. Tilting the applied load from vertical to oblique load dramatically increase the total deformation and Von Mises stress. Bone (cortical and spongy) and mucosa showed similar (equivalent) behavior under Equators and Locators attachments. Using equator attachments generated slightly less stresses on over-denture while using locators transfer less stresses to implants body and flexible caps.
\end{abstract}

\section{Introduction}

A lot of people around the world lost their teeth because of caries, periodontal disease, accidents and oral cancer. They are classified either partial or completely edentulous patients. The edentulous patients are facing many problems as the reduced number of teeth makes the chewing and mastication is more difficult which affect their normal health. The patients try to avoid the hard and tough food as they are very difficult to chew.

Edentulous patients are considered, according to the world health organization, disabled and handicapped because they are not able to masticate and speak well. Edentulism is a worldwide phenomenon. The rate of edentulism increases with age.

The latest researches show that there are no gender biases for

"Mohamed S. A. Ali, Implant faculty of Dentistry, Cairo university, Egypt, +201112114342, msaeed162016@gmail.com edentulous patients, both men and women nearly equal.

The most popular and traditional treatment for edentulous patient is the complete denture. The complete denture has a lot complications that may be local or systemic such as loss of complete denture retention and its stability, accelerated jaw bone loss, gingival hyperplasia, denture stomatitis, inconvenient, dull the senses in the mouth, repeatedly lose their fit, become more loose over time and it only provides a small fraction of the chewing power of natural teeth.

The advent of dental implant, over the last two decades, has a great effect for prosthetic management of completely edentulous patients. Per-Ingvar Brånemark, Swedish surgeon, discovered the implant in 1960's. Dental implants may be made of titanium, titanium alloy or zirconia. Zirconia implant is the most recent invention. All these materials are biocompatible with human 
body and have no adverse effects. It compensates for the function, esthetic requirements and needs minimal maintenance.

Root supported overdentures use the remaining root structure to provide stability, retention and support for the overdenture. The existence of periodontal ligaments preserve alveolar ridge, height, width, shape and decrease the natural bone loss that occurs after tooth extraction.

Dental implant attachment systems nowadays are classified into two main groups: bar and stud attachments.

The selected attachments for implant supported overdentures should have enough retentive properties to enhance the stability of the restoration the way stress is applied to implants after osseointegration was one of the important factors considered and studied in implant dentistry.

The distribution of forces in peri-implant bone has been investigated by finite element analyses in several studies. Recently, stress distribution in bone correlated with implantsupported prosthesis design has been investigated primarily by means of two-dimensional (2D) and three-dimensional (3D) finite element analyses (FEAs). Cases comparing the accuracy of these analyses found that, if detailed stress information is essential, then three dimensional modeling is mandatory.

Many different attachments available today may be used to retain implant-retained overdentures. However, the selected attachment used in implant-retained overdenture has a potential effect on implant survival rate, marginal bone loss, soft tissue complications, retention, stress distribution, maintenance complications and patient's satisfaction [1].

The finite element analysis is a reliable technique for analyzing stresses around the dental implant, bone and attachment systems. In this study we will assess applied stresses on the implants comparing between equator attachment systems and locator attachment systems in mandibular implant-retained overdenture. In-vitro study was shot in this research as the attachments are recently launched in the markets. Thus, it is preferred to investigate this new attachment system outside the patient's mouth for better understanding of its effect on the bone stresses and deformations and other finite element model components. In addition, in-vitro study can be done with less ethical and safety concern.

\section{Materials and Methods}

The 3D FEA study resembles a clinical situation where completely edentulous mandible restored with two implants retained overdenture. The overdenture was supported by two implants in the canine regions. That a finite element model was prepared based on Geng et al., [2], and El-Anwar et al. [3, 4]. Two attachment systems were studied and compared as Equator and Locator, under different load cases were tested to find out the better design from bone stresses and deformations.

The 3D FE model components as the overdenture, mucosa, implant, equators \& locators' attachment, metallic caps, rubber caps, cortical and cancellous bones were created in "Autodesk Inventor" Version 8 (Autodesk Inc., San Rafael, CA, USA), then exported as SAT files. These components were assembled in ANSYS environment (ANSYS Inc., Canonsburg, PA, USA). Where the designs of the implant and the attachment systems were taken from the manufacturer data. The system analyzed in this investigation consisted of the commonly available root form threaded titanium dental implant (Zimmer Dental Inc, USA). Locator (Zimmer Dental Inc, USA) and OT Equator (MIS Implants Technologies Ltd, dimensions were taken from manufacturer catalogues. The root form dental implant had a diameter of $4.1 \mathrm{~mm}$ (Model TSVM Implant) with $3.5 \mathrm{~mm}$ Apex Diameter, a length of $10 \mathrm{~mm}$ and the shape of the internal connection as presented in Figure 1.

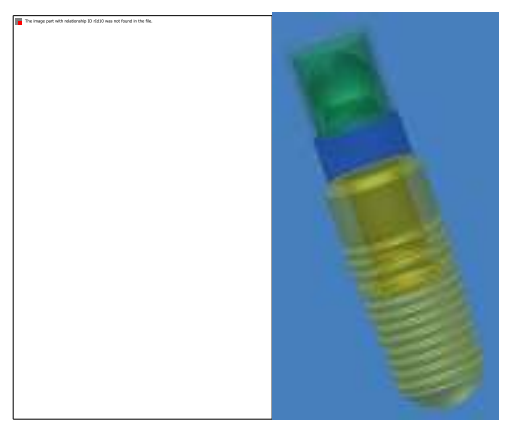

Figure 1: Locator, Equator, Rubber ring and metallic cap on Inventor screen

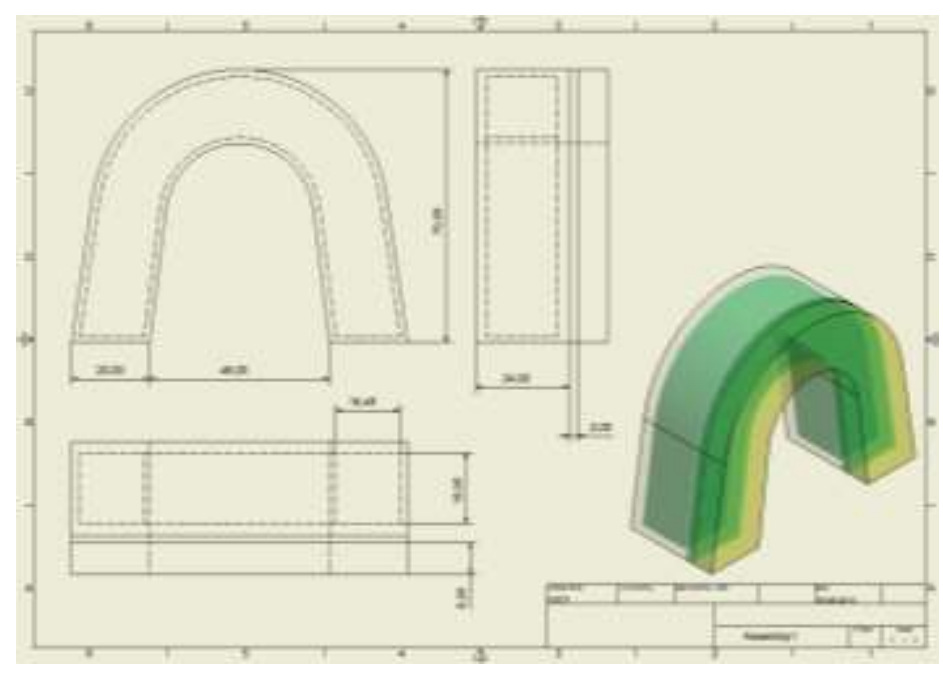

Figure 2: Mandible components on Inventor screen: assembly

Figure 2 shows all parts of the mandible as assembly as appeared on Inventor screen. All these parts in addition to the implant, abutment, and magnetic attachment were exported from Inventor as SAT files [5]. Then set of Boolean operations were carried out to assemble all the model components before meshing.

The simulated peri-implant bone included an inner layer representing cancellous bone of $22 \mathrm{~mm}$ height and $14 \mathrm{~mm}$ width covered by an outer thin layer of cortical bone of $2 \mathrm{~mm}$ thickness. The simulated covering mucosal layer was of $2 \mathrm{~mm}$ thickness. The prosthetic acrylic overdenture was simulated of height $8 \mathrm{~mm}$ and width of $8.8 \mathrm{~mm}[6,7]$.

The implants/abutment/attachment were located at their planned positions as mentioned before in canine region with inter 
implant space $20 \mathrm{~mm}$ in the inter foramina region. Perfect osseointegration was assumed to be presented between implants and bone.

All materials to be used in this study were assumed to be isotropic, homogenous and linearly elastic and its properties are listed in Table 1.

Table 1: Mechanical properties of materials used in the finite element model

\begin{tabular}{|c|c|c|}
\hline Material & $\begin{array}{c}\text { Young's Modulus } \\
{[\mathrm{MPa}]}\end{array}$ & Poisson's Ratio \\
\hline Cortical & $\mathbf{1 3 , 7 0 0}$ & $\mathbf{0 . 3 0}$ \\
\hline Cancellous & 1,370 & 0.30 \\
\hline Implant - attachment & $\begin{array}{c}110,000 \\
\text { (Per ASTM E8-04) }\end{array}$ & $\mathbf{0 . 3 3}$ \\
\hline Metallic cap & $\begin{array}{c}110,000 \\
\text { (Per ASTM E8-04) }\end{array}$ & $\mathbf{0 . 3 3}$ \\
\hline Nylon ring & $\mathbf{3 5 0}$ & $\mathbf{0 . 4 0}$ \\
\hline Mucosa & $\mathbf{1 0}$ & $\mathbf{0 . 4 0}$ \\
\hline Overdenture & $\mathbf{2 , 7 0 0}$ & $\mathbf{0 . 3 5}$ \\
\hline
\end{tabular}

Set of Boolean operations between the modeled components were performed before obtaining the complete model(s) assembled. The meshing of these components was done by 3D solid element (SOLID187) which has three degrees of freedom (translation in main axes directions) [8]. The resulted numbers of nodes and elements are listed in Table 2, and samples for these meshed components are presented as screen shots from ANSYS screen in Figure 3.

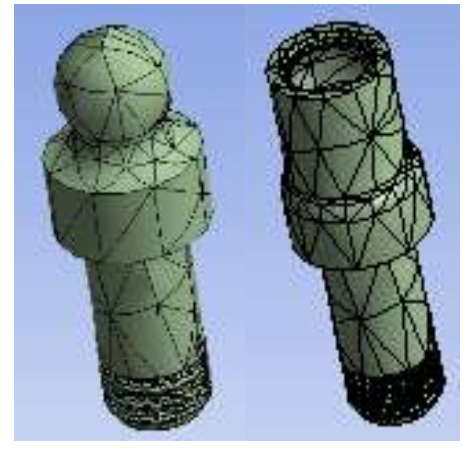

Figure 3: 3-D finite element meshes of Equator and Locator

The model was subjected to four loading conditions of $50 \mathrm{~N}$, $100 \mathrm{~N}$, and $150 \mathrm{~N}$ were investigated as vertical load placed at right molar region. Additionally, oblique load of $100 \mathrm{~N}$ was also studied when placed at an angle of $45^{\circ}$ from the lingual direction on the left premolar/molar region. The lowest plane of the model was considered fixed in the three directions as a boundary condition. The applied load was unilateral on the premolar/molar region of $50 \mathrm{~N}, 100 \mathrm{~N}, 150 \mathrm{~N}$ in vertical and in oblique 450 lingobuccal directions. The choice of a load direction was determined since the implant overdenture in an edentulous patient is subjected to a vertical biting force perpendicular to the occlusal plane and an oblique force applied on the buccal surface to represent the chewing forces. In addition, the choice of a load of $150 \mathrm{~N}$ was determined by the suggested average maximum occlusal force in complete denture patients. The load was applied on the region of premolar/molar as the occlusal surface of the distal half of the second premolar and the mesial of the first molar are considered the center of mastication where eighty percent of the force of mastication falls $[9,10]$.

Table 2: Number of nodes and elements in all meshed components

\begin{tabular}{|c|c|c|c|c|}
\hline \multirow{2}{*}{} & \multicolumn{2}{|c|}{ Equator Model } & \multicolumn{2}{c|}{ Locator Model } \\
\cline { 2 - 5 } & Nodes & Elements & Nodes & Elements \\
\hline Cortical Bone & $\mathbf{2 2 , 8 4 4}$ & $\mathbf{1 1 , 5 0 0}$ & $\mathbf{2 2 , 8 4 4}$ & $\mathbf{1 1 , 5 0 0}$ \\
\hline Spongy Bone & $\mathbf{5 3 , 1 1 5}$ & $\mathbf{3 1 , 1 7 1}$ & $\mathbf{5 3 , 1 1 5}$ & $\mathbf{3 1 , 1 7 1}$ \\
\hline 2 x Implant & $\mathbf{4 3 , 6 3 3}$ & $\mathbf{2 4 , 8 1 6}$ & $\mathbf{4 3 , 6 2 8}$ & $\mathbf{2 4 , 8 2 1}$ \\
\hline 2 x Attachment & $\mathbf{1 0 , 2 9 9}$ & $\mathbf{5 , 8 5 5}$ & $\mathbf{1 2 , 7 5 8}$ & $\mathbf{7 , 2 6 8}$ \\
\hline $\begin{array}{c}\text { 2 x Rubber } \\
\text { Ring }\end{array}$ & $\mathbf{1 , 5 1 0}$ & $\mathbf{7 5 5}$ & $\mathbf{2 , 6 2 9}$ & $\mathbf{1 , 4 3 5}$ \\
\hline 2 x Metal Cap & 1,128 & $\mathbf{5 1 6}$ & $\mathbf{1 , 7 0 3}$ & $\mathbf{7 9 5}$ \\
\hline Mucosa & $\mathbf{1 7 , 9 5 7}$ & $\mathbf{3 , 3 4 2}$ & $\mathbf{8 , 0 2 6}$ & $\mathbf{3 , 8 3 2}$ \\
\hline Overdenture & $\mathbf{1 0 , 0 5 1}$ & $\mathbf{5 , 4 5 8}$ & $\mathbf{1 0 , 0 7 3}$ & $\mathbf{5 , 4 7 8}$ \\
\hline
\end{tabular}

\section{Results}

In this section the maximum values of Von Mises stress and total deformation will be compared to extract findings from the study parameters in order to be discussed.

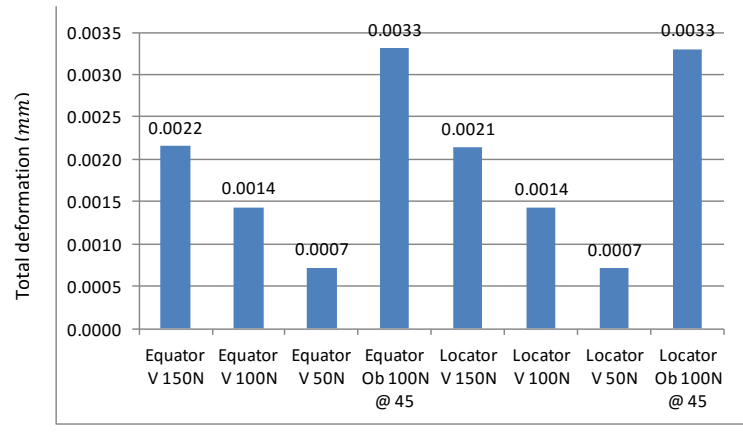

Figure 4: Total deformation on Cortical Bone

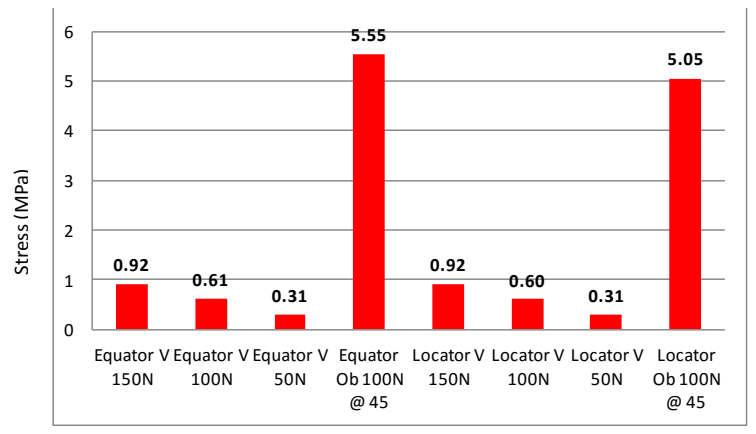

Figure 5: Von Mises stress on Cortical Bone

Cortical bone results (Figures 4, 5) showed that changing attachment type from locator to equator was ineffective on maximum Von Mises stress and deformation. Where increasing applied load increase both stresses and deformations by $0.31 \mathrm{MPa}$, and 0.7 micron per $50 \mathrm{~N}$ respectively. Oblique loading increased stresses and deformations dramatically by about $900 \%$ and $500 \%$ respectively. 


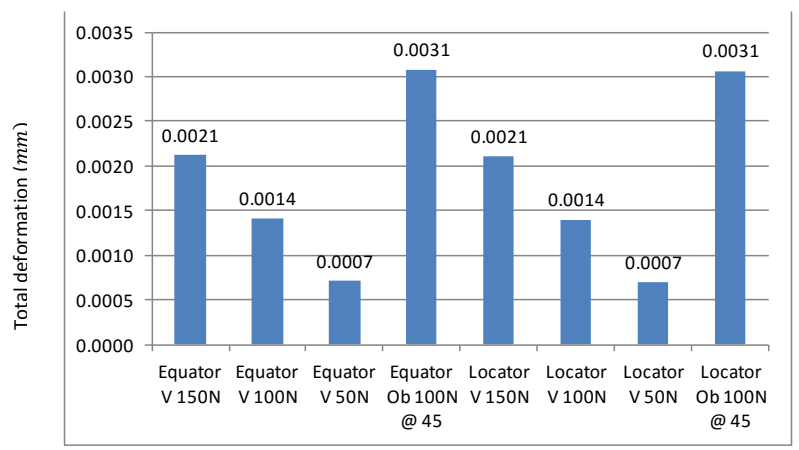

Figure 6: Total deformation on Spongy Bone

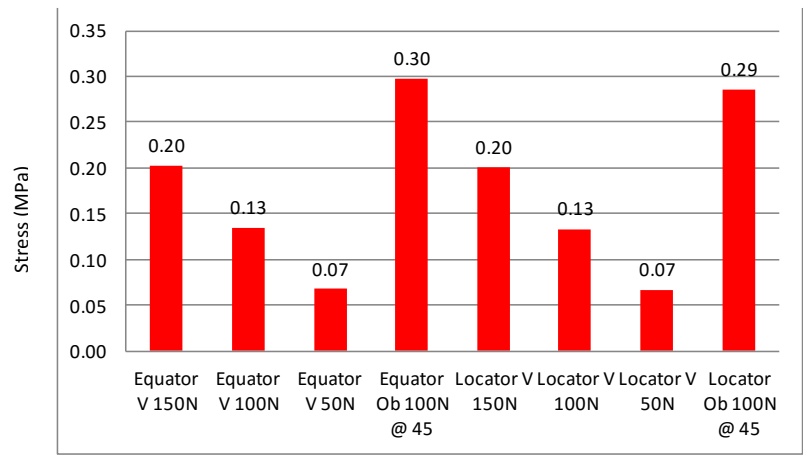

Figure 7: Von Mises stress on spongy Bone

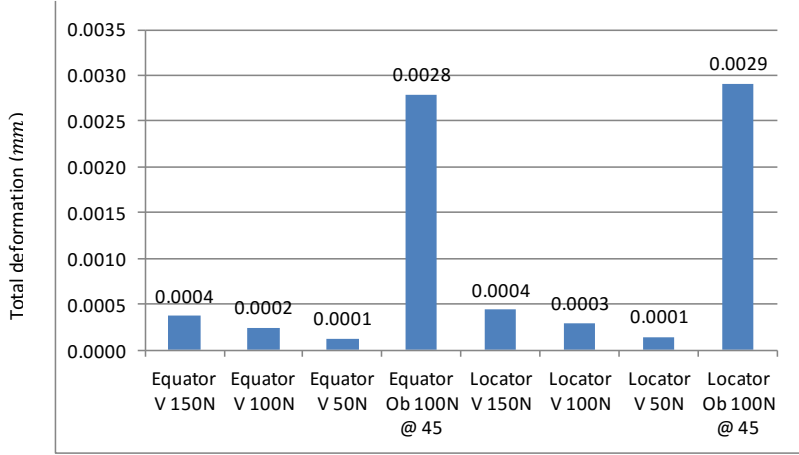

Figure 8: Total deformation on Attachments

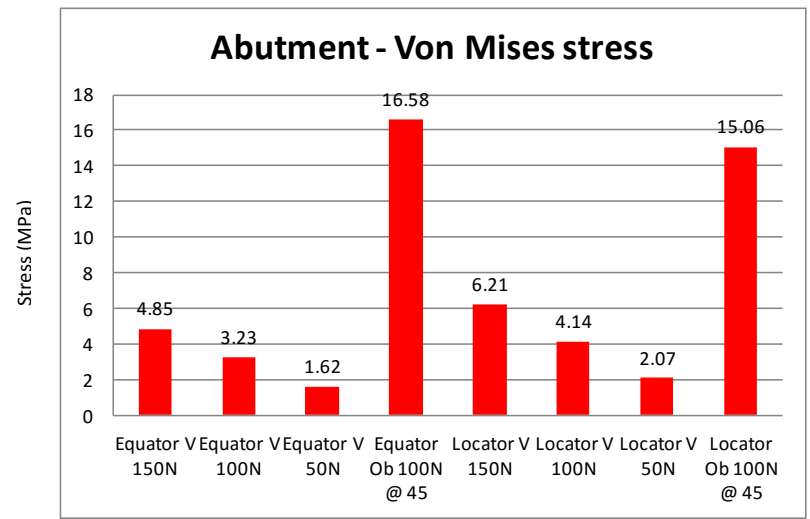

Figure 9: Von Mises stress on attachments

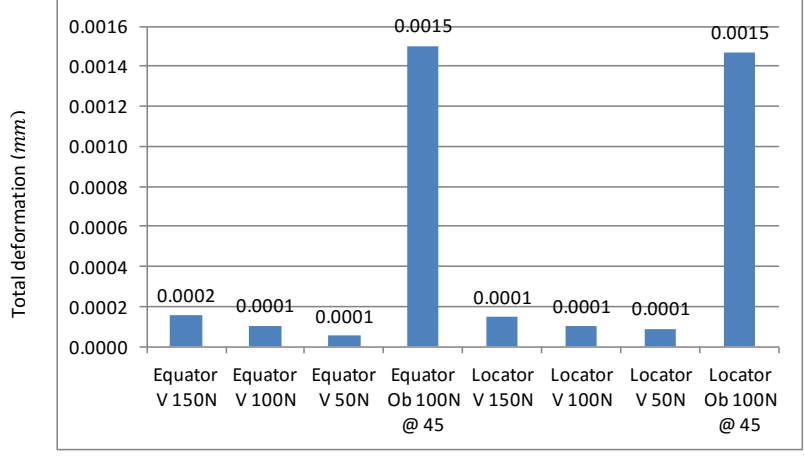

Figure 10: Total deformation on Implant

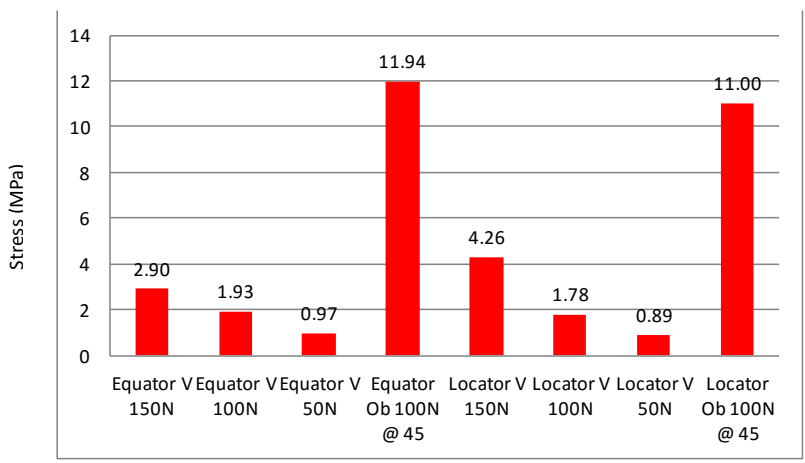

Figure 11: Von Mises stress on implant

As seen in all Figures, all components (Cortical BoneSpongy Bone- Implant- Attachments) showed safe level of stresses, that no worry from failure of any part of the model, because the resultant stresses do not exceed the physiological limits.

It seems that spongy bone (Figures 6,7 ) is also insensitive to attachment type. While increasing applied load increase both stresses and deformations by $0.07 \mathrm{MPa}$, and 0.7 micron per $50 \mathrm{~N}$ respectively. Additionally, oblique loading increased stresses and deformations dramatically by about $500 \%$.

On the other hand, (Figures 8,9) showed locator stresses were slightly less than equator ones. As the vertically applied load increase the Von Mises stress difference increase to reach about $20 \%$ less by locators in comparison to equators. While this difference was limited to $10 \%$ with the oblique loading.

Metal caps showed better performance with locators in comparison to equators. Both total deformation and Von Mises stress showed slightly less values under locators. Where all stress values were far away from yield stress.

Over-denture results comparison showed unnoticeable changes in total deformation with changing attachment type. Similarly increasing load increase mucosal total deformation by about 13.2 micron per $50 \mathrm{~N}$. While changing load direction to be oblique will increase the total deformation by about $250 \%$.

Mucosa showed minor changes in total deformation with changing attachment type. Similarly increasing load increase mucosal total deformation by about 10 micron per $50 \mathrm{~N}$. While changing load direction to be oblique will increase the total deformation by about $250 \%$. 
On the other hand equators stresses were slightly less than locator ones. As the vertically applied load increase the Von Mises stress difference increase to reach about $1 \%$ less by equators in comparison to equators. While this difference was limited to $10 \%$ with the oblique loading.

Abutment results showed negligible changes in total deformation with changing attachment type. Equators received less Von Mises stress than locators by about $40 \%$ under vertical loading. On the other hand under oblique loading locators showed better performance and less Von Mises stress by about $10 \%$.

Implant results (Figures 10, 11) indicated that total deformation less than 1 micron under vertical loading, while it jumps to 1.5 micron under oblique loading. As the vertical load increase from 50 to 100 to $150 \mathrm{~N}$ the total deformation and Von Mises stress increase. Where the extreme values appeared under oblique loading. Generally, locators transfer less stresses to implants if compared with equators.

Flexible cap showed insensitive behavior to attachment type. That slight less deformation appeared with locators in comparison to equators. On the other hand, locators transfer much less stresses to flexible caps. That indicated longer life time and longer periods between successive maintenance.

\section{Discussion}

As locators transfer much less stresses to flexible caps. That indicated longer life time and longer periods between successive maintenance. This observation could be related to that this locator's high-density resin cap that is originally designed to be incorporated into the denture base to help managing stresses. It acted as if it helped by carrying a big share of stresses to protect the simulated supporting structures; cortical and cancellous bone as well as the implant body from being stressed. [14]

As the vertical load increase the total deformation and Von Mises stress increase as the used materials were assumed to linear elastic, homogenous and isotropic. In addition, as the resultant stresses are within the linear part of stress strain curve the results will be correct and the same as what was obtained in this study even if we used full stress strain curve in defining all materials (non-linear materials).

\section{Conclusion}

All Equator attachment can be considered equivalent to locator attachment, while it may have better performance in certain situations. As the applied load at lower first molar increase the total deformation and Von Mises stress increase proportionally. Tilting the applied load from vertical to oblique load dramatically increase the total deformation and Von Mises stress. Bone (cortical and spongy) and mucosa showed similar (equivalent) behavior under Equators and Locators attachments. Using equator attachments generated slightly less stresses on overdenture, and its body in comparison to locator attachments. Using locators transfer less stresses to implants body and flexible caps, that, indicated longer lifetime and longer periods between successive maintenance. The locator attachment therefore offers a significant advantage with reduction in the problems associated with rapid component wear and failure.

\section{Conflict of Interest}

The authors declare no conflict of interest.

\section{References}

[1] F. Wang, A. Monje, W. Huang, Z. Zhang, G. Wang, Y. Wu, Maxillary Four Implant-retained Overdentures via Locator ${ }^{\circledR}$ Attachment: Intermediate-term Results from a Retrospective Study, Clin. Implant Dent. Relat. Res. doi:10.1111/cid.12335, 2016.

[2] O. Ozan, S. Ramoglu, Effect of Implant Height Differences on Different Attachment Types and Peri-Implant Bone in Mandibular Two-Implant Overdentures: 3D Finite Element Study, J. Oral Implantol. doi:10.1563/AAID-JOI-D-13-00239, 2015.

[3] Geng J, Yan W, Xu W, editors. Application of the finite element method in implant dentistry. Springer Science \& Business Media; Sep 26, 2008.

[4] El-Anwar MI, El-Taftazany EA, Hamed HA, Abd ElHay MA Influence of Number of Implants and Attachment Type on Stress Distribution in Mandibular Implant-Retained Overdentures: Finite Element Analysis. Open Access Maced J Med Sci.; 5(2):244249.Doi:10.3889/oamjms.2017.047, 2017.

[5] El-Anwar MI, Yousief SA, Soliman TA, Saleh MM, Omar WS. A Finite element study on stresses distribution of two different attachment designs under implant supported overdenture. The Saudi Dental Journal. 2015;27(4):201-7. doi: 10.1016/j.sdentj, .03.001, 2015.

[6] M.I. El-Anwar. Simple Technique to Build Complex 3D Solid Models. Proceeding of 19th International Conference on Computer Theory and Applications (ICCTA 2009), 17- 19 Oct. (2009), Alexandria, Egypt. Doi: 10.1016/j.sdentj.2015.03.001, 2009.

[7] Huang HL, Chang CH, Hsu JT, Fallgatter AM, Ko CC. Comparison of implant body designs and threaded designs of dental implants: A 3dimensional finite element analysis. Int J Maxillofac Imp. 2007; 22(4): 551-562. https://www.ncbi.nlm.nih.gov/pubmed/17929515, 2007.

[8] Lui J, Pans S, Dong J, Mo Z, Fan Y, Feng H. Influence of implant number on the biomechanical behavior of mandibular implantretained/supported overdentures: a three-dimensional finite element analysis. J Dent. 2013; 41(3): 241-249, 2013. Doi: 10.1016/j.jdent.2012.11.008

[9] Fromentin O, Lassauzay C, Abi Nader S, Feine J, de Albuquerque Junior RF. Testing the retention of attachments for implant overdentures - validation of an original force measurement system. J Oral Rehabil. 2010 Jan;37(1):54-62, 2010. DOI: $10.1111 /$ j.1365-2842.2009.02020.x

[10] A.D. Schwitalla, M. Abou-Emara, T. Spintig, J. Lackmann, W.D. Müller, Finite element analysis of the biomechanical effects of PEEK dental implants on the peri-implant bone, J. Biomech,. (2015). doi:10.1016/j.jbiomech.2014.11.017. 